\title{
Astroglial Responses to Amyloid-Beta Progression in a Mouse Model of Alzheimer's Disease
}

\author{
Malin Olsen, ${ }^{1}$ Ximena Aguilar, ${ }^{1}$ Dag Sehlin, ${ }^{1}$ Xiaotian T. Fang, ${ }^{1}$ Gunnar Antoni, ${ }^{2,3}$ \\ Anna Erlandsson, ${ }^{1}$ Stina Syvänen $\mathbb{0}^{1}$ \\ ${ }^{1}$ Department of Public Health and Caring Sciences/Geriatrics, Rudbeck Laboratory, Uppsala University, Dag Hammarskjölds väg 20, SE- \\ 751 85, Uppsala, Sweden \\ ${ }^{2}$ Department of Medicinal Chemistry, Preclinical PET Platform, Uppsala University, Dag Hammarskjölds väg 20, SE-751 83, Uppsala, \\ Sweden \\ ${ }^{3}$ PET Centre, Uppsala University Hospital, Entrance 70, Sjukhusvägen 10, SE-75185, Uppsala, Sweden
}

\begin{abstract}
Purpose: Alzheimer's disease (AD) is a neurodegenerative disorder characterized by amyloidbeta $(A \beta)$ deposition, hyperphosphorylation of tau, and neuroinflammation. Astrocytes, the most abundant glial cell type in the nervous system, respond to neurodegenerative disorders through astrogliosis, i.e., converting to a reactive inflammatory state. The aim of this study was to investigate how in vivo quantification of astrogliosis using positron emission tomography (PET) radioligand deuterium-L-[ $\left[{ }^{11} \mathrm{C}\right]$ deprenyl $\left(\left[{ }^{11} \mathrm{C}\right] \mathrm{DED}\right)$, binding to enzyme monoamine oxidase-B (MAO-B) which is overexpressed in reactive astrocytes during $A D$, corresponds to expression of glial fibrillary acidic protein (GFAP) and vimentin, i.e., two well-established markers of astrogliosis, during $A \beta$ pathology progression.

Procedures: APP Arcswe mice $(n=37)$ and wild-type (WT) control mice $(n=23), 2-16$-month old, were used to investigate biomarkers of astrogliosis. The radioligand, $\left[{ }^{11} \mathrm{C}\right] \mathrm{DED}$, was used as an in vivo marker while GFAP, vimentin, and MAO-B were used to investigate astrogliosis and macrophage-associated lectin (Mac-2) to investigate microglia/macrophage activation by immunohistochemistry of the mouse brain. $A \beta$ and GFAP levels were also measured with ELISA in brain homogenates.

Results: The intrabrain levels of aggregated $A \beta$ and reactive astrocytes were found to be

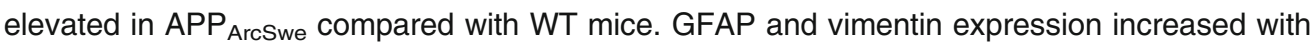
age, i.e., with $A \beta$ pathology, in the $A P_{\text {Arcswe }}$ mice. This was not the case for in vivo marker $\left[{ }^{11} \mathrm{C}\right] \mathrm{DED}$ that showed elevated binding of the same magnitude in $\mathrm{APP}$ Arcswe mice compared with WT mice at both 8 and 16 months. Further, immunohistochemistry indicated that there was limited co-expression of MAO-B and GFAP.

Conclusions: MAO-B levels are increased early in A $\beta$ pathology progression, while GFAP and vimentin appear to increase later, most likely as a consequence of abundant $A \beta$ plaque formation. Thus, $\left[{ }^{11} \mathrm{C}\right] \mathrm{DED}$ is a useful PET radioligand for the detection of changes in MAO-B at an early stage of
\end{abstract}

Electronic supplementary material The online version of this article (https:// doi.org/10.1007/s11307-017-1153-z) contains supplementary material, which is available to authorized users.

Correspondence to: Stina Syvänen; e-mail: stina.syvanen@pubcare.uu.se 


\begin{abstract}
$A D$ progression but does not measure the total extent of astrogliosis at advanced stages of $A \beta$ pathology.
\end{abstract}

Key words: PET, Amyloid-beta, Astrocytes, Astrogliosis, MAO-B, GFAP, Vimentin, $\left[{ }^{11} \mathrm{C}\right] \mathrm{DED}$

\section{Introduction}

Alzheimer's disease (AD) is the most common form of dementia and estimated to affect around 50 million people worldwide. The pathophysiology of $\mathrm{AD}$ is complex and involves cellular processes, such as amyloid beta $(A \beta)$ deposition into amyloid plaques, hyperphosphorylation of tau, and aggregation of tau into neurofibrillary tangles, oxidative stress, apoptosis, and neuroinflammation.

According to the amyloid cascade hypothesis, mismetabolism of $\mathrm{A} \beta$ is the first event in $\mathrm{AD}$ development and all other neuropathological features of AD are secondary events, induced by the $A \beta$ pathology [1]. Monomeric $A \beta$ is very prone to aggregate into smaller and larger soluble $A \beta$ assemblies, which can then further aggregate into insoluble fibrils, which eventually deposit as $\mathrm{A} \beta$ plaques. Originally plaques were considered to be neurotoxic to neurons, but several studies indicate that soluble $\mathrm{A} \beta$ aggregates, e.g., oligomers and protofibrils, are the toxic forms of $A \beta$ and that these smaller aggregates are capable of inducing neuronal death [2-7].

It is debated whether the inflammatory changes occurring in the brain during $\mathrm{AD}$ are caused by or are causing the pathology. Neuroinflammation has beneficial roles, i.e., by inducing phagocytosis of apoptotic cells and debris and by inducing tissue repair processes with the primary goal of protecting the CNS from injury and diseases. However, inflammatory activities that are proceeding uninhibited can cause cellular dysfunction and may eventually be contributing to the pathophysiology of $\mathrm{AD}$ [8]. For example, it is known that the expression of pro-inflammatory molecules, such as IL-1, IL-6, and TNF- $\alpha$, is altered in an AD brain [9].

Astrocytes are the most abundant glial cell type. Until quite recently, the function of astrocytes was believed to be a structural support for the neuronal network. However, it has now become clear that astrocytes are responsible for a variety of important functions in the brain including metabolic support of neurons, modification of synapse signaling, recycling of neurotransmitters, blood-brain barrier regulation, and glymphatic clearance [10-12].

Reactive astrogliosis is a process in which astrocytes convert to an inflammatory state. This process is triggered by some type of pathological condition in the microenvironment surrounding the astrocytes, e.g., the presence of mis-folded proteins [13]. For example, reactive astrocytes are together with microglia found in the close proximity to A $\beta$ plaques [14, 15]. The tightly packed glial cells might protect the surrounding brain tissue from the plaque itself and from toxic, soluble $\mathrm{A} \beta$ species that might appear at the plaque site. However, the glial cells play a rather complex role during the disease process and are known to secrete cytokines and other factors that could be either neurotoxic or neuroprotective [16]. For example, an increased expression of pro-inflammatory molecules can stimulate $\gamma$-secretase activity and enhance the processing of APP, potentially leading to an exacerbation of the $\mathrm{A} \beta$ pathology [17].

Reactive astrocytes are phagocytic cells that are able to ingest dead cells, neuronal synapses, and protein aggregates of $A \beta$ and $\alpha$-synuclein [18-22]. Especially in early stages of $\mathrm{AD}$, astrocytes appear to be even more efficient than microglia in engulfing $A \beta$ [22]. However, their exact role in the pathophysiology is not well understood [8]. One of the hallmarks of astrogliosis is the increased expression of the intermediate filament proteins glial fibrillary acidic protein (GFAP) and vimentin.

L-Deprenyl is an irreversible inhibitor of the enzyme monoamine oxidase B (MAO-B). MAO-B is found on the outer membrane of the mitochondria, predominately in astrocytes in the brain [23]. The positron emission tomography (PET) radioligand deuterium-L- $\left[{ }^{11} \mathrm{C}\right]$ deprenyl $\left(\left[{ }^{11} \mathrm{C}\right] \mathrm{DED}\right)$ displays high specificity and affinity for MAO-B [24]. The enzyme is overexpressed in reactive astrocytes, such as those for example in AD. Several clinical PET studies have thus suggested that $\left[{ }^{11} \mathrm{C}\right] \mathrm{DED}$ can be used as a PET ligand for measuring the MAO$\mathrm{B}$ activity in $\mathrm{AD}$ brains as an in vivo marker for early disease progression [25-29].

There are currently two standpoints on whether astrogliosis is preceding the plaque pathology or if the plaque pathology is initiating the astrogliosis. Based on recent studies with $\left[{ }^{11} \mathrm{C}\right] \mathrm{DED}$ PET imaging of astrogliosis it has been suggested that astrogliosis occurs early in AD and precedes the occurrence of insoluble plaques [30], while other studies have found an increase of astrogliosis in parallel with the progression in Braak stages [31]. The aim of this study was to investigate how in vivo quantification of astrogliosis using PET radioligand $\left[{ }^{11} \mathrm{C}\right] \mathrm{DED}$ corresponds to the amount of reactive astrocytes found in different brain regions using GFAP and vimentin immunohistochemistry, and GFAP ELISA in isolated brain tissue from young and old APP ArcSwe and wild-type control (WT) mice.

\section{Methods}

\section{Animals}

Male $(n=21)$ and female $(n=16) \mathrm{APP}_{\text {ArcSwe }}$ mice, obtained by in-house breeding on a $\mathrm{C} 57 \mathrm{bl} / 6$ background, and non- 
transgenic male $(n=10)$ and female $(n=13)$ WT littermates of the same age were used. $\mathrm{APP}_{\text {ArcSwe }}$ mice show elevated levels of soluble $A \beta$ aggregates already at a very young age and a developing plaque pathology starting at around 67 months of age [32,33]. A $\beta$ pathology first appears as intraneuronal inclusions in the cerebral cortex and hippocampus and later as larger extracellular assemblies. Pathology then spreads to thalamus and striatum. Opposite to many other mouse models of $\mathrm{A} \beta$ pathology, $\mathrm{APP}_{\text {ArcSwe }}$ mice display dense-cored plaques resembling those found in human $\mathrm{AD}$ brains. The mice were housed at an animal facility at Uppsala University at $20-22{ }^{\circ} \mathrm{C}$, with access to food and water ad libitum on a 12 -h light/dark cycle. At the time of euthanisation, mice were deeply anesthetized with 2.7-3.2 \% isoflurane (Baxter Medical AB, Kista, Sweden) followed by intracardiac perfusion with $50 \mathrm{ml}$ physiological saline during $2 \mathrm{~min}$. After perfusion, the brain was removed from the cranium and divided by the midline into two pieces. The left hemisphere was snap frozen on dry ice to be used for biochemical quantification of $A \beta$ and GFAP. The right hemisphere was placed in paraformaldehyde for $24 \mathrm{~h}$. After $24 \mathrm{~h}$, it was cryoprotected in sucrose $(10,20$, and finally $30 \%$ ) and stored in $30 \%$ sucrose at $4{ }^{\circ} \mathrm{C}$ until cryosectioned for immunohistochemical analysis. The cerebellum, which is largely devoid of $\mathrm{A} \beta$ pathology [34], was removed before homogenization of the left hemisphere. Details are provided in Electronic Supplementary Material (ESM).

\section{PET Scanning}

The PET radioligand $\left[{ }^{11} \mathrm{C}\right] \mathrm{DED}$ was synthesized as previously described [35]. Four groups of animals were investigated; 8month-old $\mathrm{APP}_{\text {ArcSwe }}(n=5), 8$-month-old WT $(n=5)$, 16month-old $\mathrm{APP}_{\text {ArcSwe }}(n=4)$, and 16-month-old WT $(n=6)$. Animals were anesthetized with isoflurane and the tail vein was cannulated for $\left[{ }^{11} \mathrm{C}\right] \mathrm{DED}$ administration. The animal was then immediately placed in a prone position on a pre-heated bed in the gantry of the PET/CT scanner (intrinsic resolution $1.35 \mathrm{~mm}$, Triumph Trimodality System, TriFoil Imaging, Inc., Northridge, CA, USA). Anesthesia was maintained throughout the study using $1.5-2.0 \%$ isoflurane in a $0.5-1 / \mathrm{min}$ flow of $50 \%$ oxygen and $50 \%$ medical air. $\left[{ }^{11} \mathrm{C}\right] \mathrm{DED}, 11.1 \pm 4.2 \mathrm{MBq}$ $(5.8 \pm 8.9 \mathrm{GBq} / \mu \mathrm{mol})$ in $120 \mu \mathrm{l}$, was injected via the tail vein at the start of the PET scan. The acquisition time in the PET scanner was $30 \mathrm{~min}$, followed by a CT examination for $3 \mathrm{~min}$ with a field of view (FOV) of $8 \mathrm{~cm}$. A terminal blood sample from the heart was obtained $60 \mathrm{~min}$ after injection of the radioligand. The brain was then isolated as described above. Radioactivity in the blood and the frozen brain samples was measured with a $\gamma$-counter (1480 WizardTM, Wallac Oy, Turku, Finland).

A MLEM 2D algorithm (ten iterations) and filtered back projection (FBP) was used to reconstruct the PET data and the CT raw files, respectively. The PET image matrix size was
$160 \times 160 \times 128$ with a voxel size of $0.5 \times 0.5 \times 0.59 \mathrm{~mm}^{3}$. Imaging software Amide 1.0.4 [36] was used to manually align the PET and CT images according to a previously described process [34]. In short, a MRI-based mouse brain atlas [37] was first aligned with the $\mathrm{CT}$. This atlas contained outlined regions of interest for hippocampus, striatum, thalamus, cerebral cortex and cerebellum. The PET images were then aligned with the CT, and the regions of interest outlined in the MRI-atlas were transferred to the PET images. Binding potential $\left(\mathrm{BP}_{\mathrm{nd}}\right)$ using time-activity curves from the whole scan time of $30 \mathrm{~min}$ was obtained in hippocampus, striatum, thalamus, and cerebral cortex using the simplified reference tissue model (SRTM) [38] with the cerebellum as reference region in Pmod (PMOD Technologies Ltd., Zürich, Switzerland). The cerebral cortex region did not include the prefrontal cortex as the measured activity in this part was confounded by spill-over from a hot-spot frontal to the brain (see results section).

\section{Immunohistochemistry}

Immunohistochemistry was performed to evaluate the expression of $\mathrm{A} \beta_{1-42}$, GFAP, Vimentin, macrophageassociated lectin (Mac-2) and MAO-B in mice aged 8, 12, and 16 months $\left(n=4 \mathrm{APP}_{\text {Arc-Swe }}, n=2 \mathrm{WT}\right.$ for each age group). The brains were collected as described above and were cryosectioned (HM500, Microm GmbH, Walldorf, Germany) in 20- $\mu$ m-thick sagittal sections ( $n \geq 4$ sections per mouse). All steps were performed at room temperature (RT) unless mentioned otherwise. Detailed protocols are provided in the ESM.

\section{Biochemical Analysis of GFAP and A P Pathology}

To further analyze the protein concentration of GFAP in $\mathrm{APP}_{\text {ArcSwe }}$ mice in relation to disease progression, a sandwich ELISA was performed in brain homogenates (lysates) obtained from mice aged 2, 4, 6, 8, 12, and 16 months ( $n=4 \mathrm{APP}_{\text {Arc-Swe }}, n=2 \mathrm{WT}$ for each age group). A detailed protocol is provided in the ESM. Levels of A $\beta 40$, corresponding to total plaque load, was measured in the formic acid treated brain homogenates. The ELISA was performed as previously described [34]. In addition to $A \beta 40$, soluble $A \beta$ protofibril levels in brain TBS homogenates was measured as previously described $[34,39]$. $\mathrm{A} \beta$ concentrations were determined from a standard curve of serially diluted synthetic $A \beta 40$ and $A \beta$ protofibrils respectively. Both $A \beta 40$ and $A \beta$ protofibril levels were studied in the same groups of mice aged $4,8,12$, and 16 months $(n=5$ $\mathrm{APP}_{\text {Arc-Swe }}, \mathrm{n}=5 \mathrm{WT}$ for each age group).

\section{Statistics}

The data was analyzed with two-way $\left(\mathrm{PET} \mathrm{BP}_{\mathrm{ND}}\right)$ or oneway (ELISA measured concentrations) ANOVA, using 
Bonferroni's post hoc test. All data were analyzed in GraphPad Prism (version 6.07). The data are reported as mean \pm standard deviation (SD). Significance levels, after Bonferroni correction, were labeled as $* p$ value $<0.05$ ), ${ }^{* *} p$ value $<0.01$ ), and ${ }^{* * *} p$ value $<0.001$ ).

\section{Results}

\section{PET Scanning}

The PET radioliagnd $\left[{ }^{11} \mathrm{C}\right] \mathrm{DED}$ was rapidly and abundantly distributed to the brain in both $\mathrm{APP}_{\text {ArcSwe }}$ and WT mice. The wash-out from the brain was also fast with intrabrain concentrations stabilizing around $10 \mathrm{~min}$ post-injection. PET images also revealed a very high radioligand concentration in a region, probably the Harderian gland, frontal to the brain (Fig. 1). Thus, $\mathrm{BP}_{\mathrm{ND}}$ values based on the whole cortex were regarded as confounded by spill-over from this hot spot. Instead, a cortex region without the prefrontal part was used for analysis. Ex vivo measured radioactivity in isolated blood and whole brain samples at $60 \mathrm{~min}$ after administration of $\left[{ }^{11} \mathrm{C}\right] \mathrm{DED}$ was used to calculate a brain-toblood concentration ratio. This ratio was $1.1 \pm 0.2$ (APP ${ }_{\text {ArcSwe }} 16$ months), $1.1 \pm 0.5$ (WT 16 months), $1.1 \pm 0.1\left(\mathrm{APP}_{\text {ArcSwe }} 8\right.$ months), and $1.0 \pm 0.2$ (WT 8 months).

$\mathrm{BP}_{\mathrm{ND}}$ values are shown in Fig. 2. Post hoc analysis revealed that 16-month-old $\mathrm{APP}_{\text {ArcSwe }}$ mice displayed significantly higher $\mathrm{BP}_{\mathrm{ND}}(2.3$-fold $)$ in the thalamus compared with 16-month-old WT mice $(p=0.016)$. Although this genotype-dependent trend was also observed in the other studied regions, it was not significant probably due to a rather large intragroup variation $(p=0.13$ in hippocampus, $p=0.53$ in striatum, $p=0.11$ in cortex). Age was not found to have a significant impact on $\mathrm{BP}_{\mathrm{ND}}$, although there was a small trend towards higher values in 16-month-old $\mathrm{APP}_{\text {ArcSwe }}$ mice compared with 8-month-old $\mathrm{APP}_{\text {ArcSwe }}$ mice, while the opposite was found for WT mice, i.e., younger WT mice displayed higher $\mathrm{BP}_{\mathrm{ND}}$ than old WT mice.

\section{Immunohistochemistry}

\section{$A \beta, G F A P$, and $M a c-2$}

Distinct plaque formation in the brain was observed in the 8month-old $\mathrm{APP}_{\text {ArcSwe }}$ mice, although some plaque pathology was found already in 6-month-old mice. The plaque formation was mainly seen in cortex, thalamus and hippocampus. In the 8-month $\mathrm{APP}_{\text {ArcSwe }}$ mice, a slight increase in GFAP-positive cells was found adjacent to the plaques in the cortex and hippocampus. In the 12-month $\mathrm{APP}_{\text {Arcswe }}$ brains, a pronounced increase of GFAP-positive cells could be seen around the plaques in the same regions, with an additional expression in thalamus. In the brains of the 16-month-old $\mathrm{APP}_{\text {ArcSwe }}$ mice, GFAP-positive cells were found densely in the cortex, hippocampus, and thalamus, not only surrounding the plaques (Figs. 3 and 4). Astrocytes with a lower GFAP expression were also distributed in various regions of the brain.

When plaque formation was observed, Mac-2-positive cells, i.e., activated microglia/macrophages, were found surrounding the $A \beta$ deposits in the cortex, hippocampus, and thalamus (Fig. 3). It was difficult to distinguish separate Mac-2-positive cells from each other as they were clustered together. Interestingly, a few cells at all ages were double positive for GFAP and Mac-2.

Brains isolated from young $\mathrm{APP}_{\text {ArcSwe }}$ mice with no plaque pathology displayed a comparable expression pattern of astrocytes and microglia as brains from WT mice (Figs. 3 and 4). In these mice, the expression of GFAP was found to be relatively low, and the positive cells were predominantly found in regenerative areas, surrounding the lateral ventricle and in the hippocampus, indicating they were mainly neuronal precursor cells. Very few Mac-2-positive cells were found in wild-type mice and in the younger $\mathrm{APP}_{\text {ArcSwe }}$ mice with no visible plaque pathology.

\section{Vimentin}

To further investigate the astrocytic response to plaque formation, another reactive astrocytic marker, vimentin, was studied. A similar appearance of vimentin-positive cells to the GFAP-positive cells was seen, however, the expression pattern was slightly different from that of GFAP (Fig. 4). Vimentin was found to have an overall low expression in all regions of the brain at early ages. When plaque formation was observed in the 8-month-old $\mathrm{APP}_{\text {ArcSwe }}$ mice, the vimentin expression increased in the cortex, and in the 12month-old $\mathrm{APP}_{\text {ArcSwe }}$ mice, the expression also increased in thalamus. The expression of vimentin in hippocampus remained quite low even in the older mice where plaque formation was observed. A main difference in the expression pattern between vimentin and GFAP was seen in the 16month-old $\mathrm{APP}_{\text {ArcSwe }}$ mice, where vimentin-positive cells were only located distinctly around the plaques, while GFAP-positive cells were found throughout the brain. Many of the reactive astrocytes co-expressed GFAP and vimentin. Among the cells only expressing one of the markers, there were more single positive cells for GFAP than for vimentin. The expression of vimentin in the WT mice was very low and was only found in the hippocampus and surrounding the ventricles.

\section{$M A O-B$}

Expression of MAO-B was also investigated with immunohistochemistry in $\mathrm{APP}_{\text {ArcSwe }}$ and WT mice of different ages. However, no significant differences in expression levels 


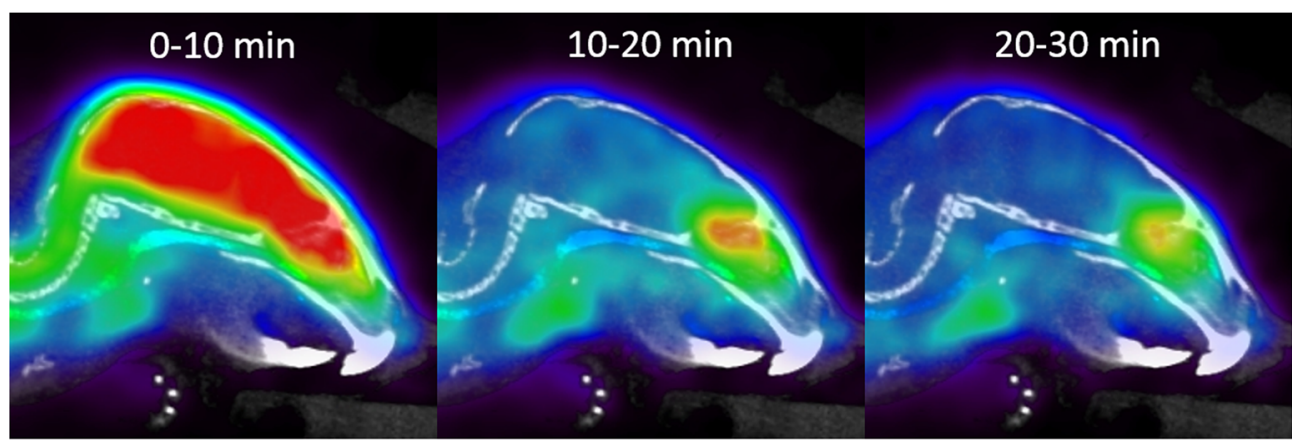

$0 \mathrm{MBq} / \mathrm{mL}$

$1 \mathrm{MBq} / \mathrm{mL}$

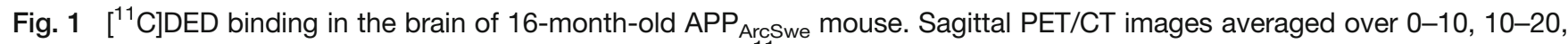
and $20-30 \mathrm{~min}$, respectively, after injection of $8 \mathrm{MBq}\left[{ }^{11} \mathrm{C}\right] \mathrm{DED}$. After initial high and homogenous brain distribution, concentrations decreased with some longer retention times in midbrain and cortical regions. $\left[{ }^{11} \mathrm{C}\right] \mathrm{DED}$ also showed high uptake in a region frontal to the brain, most likely the Harderian glands.

between the different groups were observed. Interestingly, there was very little co-localization between MAO-B and GFAP (Fig. 5).

\section{Biochemical Quantification of GFAP and A Protofibrils}

To further evaluate the expression pattern of astrocytic markers observed with immunohistochemistry, the expression of GFAP was studied in a sandwich ELISA. An optical density (OD) of GFAP was obtained from the ELISA. A significant difference was found between the 16-month-old $\mathrm{APP}_{\text {Arswe }}$ mice and the WT group $(p<0.001)$ and between the 12-month $\mathrm{APP}_{\text {ArcSwe }}$ mice and the WT group $(p<0.01)$. These old $\mathrm{APP}_{\text {ArcSwe }}$ mice also displayed significantly more GFAP than younger APP Arcswe $_{\text {mice (Fig. 6a) }}(p<0.001$ 16 months $v s .2$ and 4 months, $p<0.01$ for 16 months $v s .6$ and 8 months, $p<0.01$ for 12 months vs. 2 and 4 months). In line with the age-dependent increase in GFAP levels, both total $A \beta 40$ and TBS-soluble $A \beta$ protofibril levels increased with age in the $\mathrm{APP}_{\text {ArcSwe }}$ mice (Fig. 6b, c). For $\mathrm{A} \beta 40$, corresponding to total plaque load [32, 40], there was a large increase between 8 and 12 months.

\section{Discussion}

Neuroinflammation is a pathophysiologic event involved in $\mathrm{AD}$ where activation of astrocytes seems to be a key feature. The present study aimed at comparing in vivo PET and ex vivo markers for astrogliosis with levels of aggregated $A \beta$ in $\mathrm{APP}_{\text {ArcSwe }}$ mice during pathology progression. The in vivo marker and $\mathrm{PET}$ radioligand $\left[{ }^{11} \mathrm{C}\right] \mathrm{DED}$ binding to MAO-B, which is overexpressed in reactive astrocytes, showed an increasing trend in $\mathrm{APP}_{\text {ArcSwe }}$ mice compared with WT. However, there was no difference in $\left[{ }^{11} \mathrm{C}\right] \mathrm{DED}$ binding between 8- and 16-month-old $\mathrm{APP}_{\text {ArcSwe }}$ mice, suggesting that MAO-B levels do not increase with further increasing amount of aggregated $A \beta$ and potentially that elevated MAO-B levels are an early event during $A \beta$ pathology progression. In fact, the major increase in $A \beta$ deposition was found between 8 and 12 months, while MAO-B levels appeared to be elevated already at 8 months. These results are also in line with a previous study that
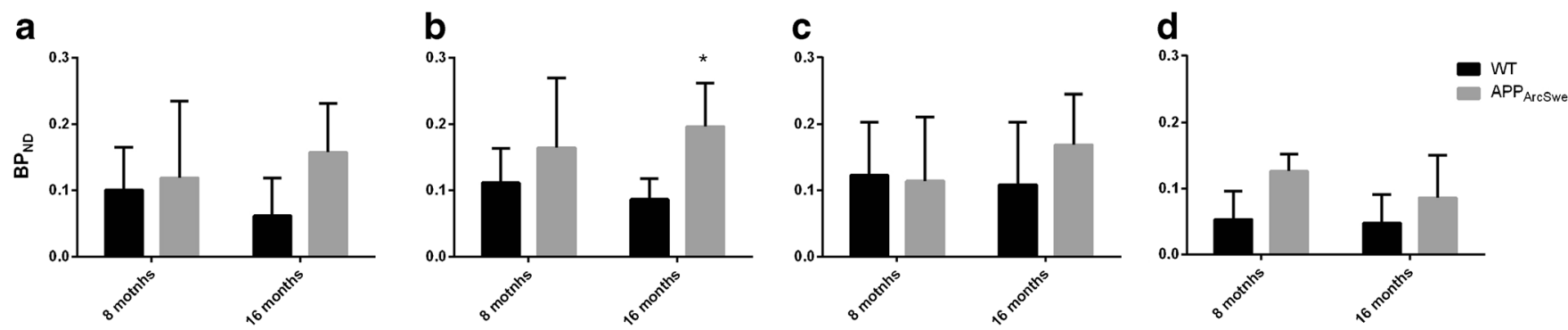

Fig. 2 Binding of $\left[{ }^{11} \mathrm{C}\right] \mathrm{DED}$ in brain of $\mathrm{APP}_{\text {ArcSwe }}$ and WT mice. Binding potential $\left(\mathrm{BP}_{\mathrm{ND}}, 0-30 \mathrm{~min}\right)$ using SRTM in a hippocampus, $\mathbf{b}$ thalamus, $\mathbf{c}$ striatum and $\mathbf{d}$ cerebral cortex. The frontal parts of cerebral cortex region was omitted from the analysis due to spill-over from a hot spot frontal to the brain. There was a trend indicating that BP ND was elevated in APP ArcSwe $_{\text {e }}$ mice compared with WT mice. The difference between WT and APP ArcSwe was only significant in 16-month-old mice in the region of thalamus. ( $n=5$ in 8-month-old WT and APP Arcswe groups, $n=6$ in 16-month-old WT group, and $n=4$ in 16-monthold $\mathrm{APP}_{\text {ArcSwe }}$ group). 

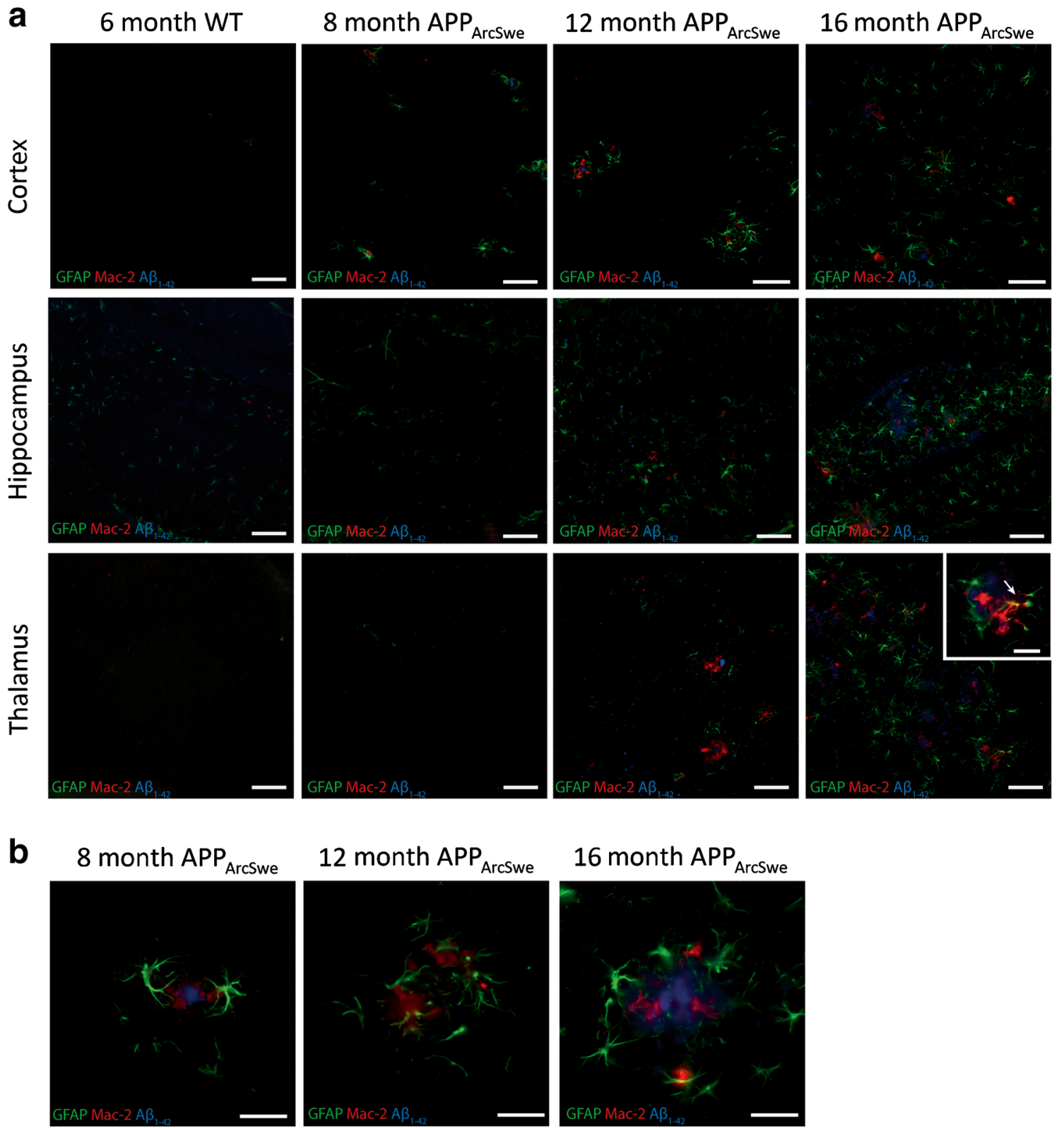

Fig. 3 Visualization of reactive astrocytes and microglia in brains isolated from 8- to 16-month-old mice. In all images, astrocytes are detected in green by anti-GFAP (Sigma Aldrich, G3893), microglia are detected in red by anti-Mac-2 (Cedarlane, CL8942AP), and A $\beta$ is detected in blue by anti-A 342 (Life Technologies, 700,254). a Images of GFAP-, Mac-2-, and A $42-$ stained brains from APP Arc-Swe and WT mice of different ages. Horizontal rows show the expression in cortex, hippocampus, and thalamus. White arrow (inset) indicates double-labeled cells. All images were taken at $\times 20$ except for the inserted images that were taken with $\times 63$ oil immersion objective. Scale bars represent $50 \mu \mathrm{m}(20 \mu \mathrm{m}$ in inserted images). b Images of GFAP-, Mac-2-, and AB42-stained brains from 8- to 16-month $\mathrm{APP}_{\text {Arc-Swe }}$ mice in cortex in the vicinity of aggregated $A \beta$; higher magnification than in (a). All images were taken with $\times 63$ oil immersion objective. Scale bars represent $20 \mu \mathrm{m}$.

reported elevated $\left[{ }^{11} \mathrm{C}\right] \mathrm{DED}$ binding in $\mathrm{APP}_{\text {swe }}$ mice compared with WT mice [30]. Somewhat contradictory to the present study, this previous study showed higher $\left[{ }^{11} \mathrm{C}\right] \mathrm{DED}$ binding in young 6-month-old $\mathrm{APP}_{\text {swe }}$ mice compared with older mice. This decline in $\left[{ }^{11} \mathrm{C}\right] \mathrm{DED}$ binding between 6-month-old $\mathrm{APP}_{\text {swe }}$ mice and older mice could, however, not be confirmed by in vitro autoradiography [30]. One limitation of the present $\left[{ }^{11} \mathrm{C}\right] \mathrm{DED}$ data is the low number of animals in each group, and that animals younger than 8 months were not investigated with PET.

During AD, an elevation of GFAP-positive cells has been shown in the brain in parallel with the progression of Braak stages [31]. Vimentin is rarely expressed in astrocytes in the mature, healthy brain, and only by precursor cells in regions where neurogenesis occurs. However, in reactive astrocytes, activated as a result of, for example, a brain insult, vimentin 

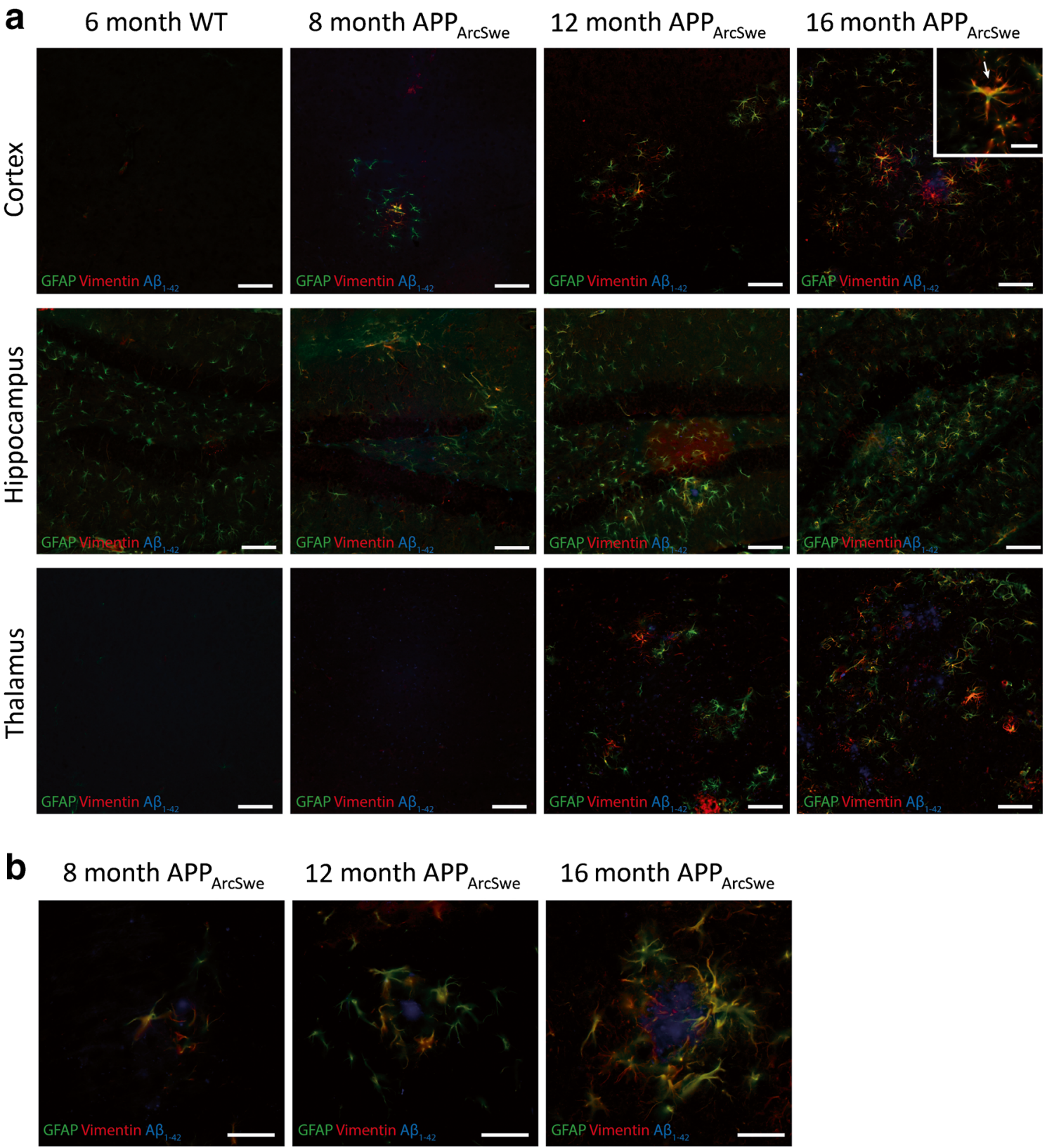

Fig. 4 Visualization of reactive astrocytes in brains isolated from 8 -to 16-month mice. In all images, astrocytes are detected in green by anti-GFAP (Sigma Aldrich, G3893) and in red by anti-vimentin (Millipore, AB5733), and amyloid plaques are detected in blue by anti-Aß42 (Life Technologies, 700,254). a Images of GFAP-, vimentin-, and Aß42-stained brains from APP Arc-Swe ${ }_{\text {and }}$ WT mice of different ages. Horizontal panels show the expression in cortex, hippocampus, and thalamus. White arrows (inset) indicate examples of double-labeled cells. All images were taken at $20 \times$ except for the inserted images that were taken with $63 \times$ oil immersion objective. Scale bars represent $50 \mu \mathrm{m}(20 \mu \mathrm{m}$ in inserted images). b Images of GFAP-, vimentin-, and A $442-$ stained brains from 8- to 16-month $\mathrm{APP}_{\text {Arc-Swe }}$ mice in the cortex in the vicinity of aggregated $A \beta$; higher magnification than in (a). All images were taken with $\times 63$ oil immersion objective. Scale bars represent $20 \mu \mathrm{m}$.

expression is intensively upregulated in astrocytes in the damaged regions. GFAP expression is in addition to the damaged area also diffusely observed in the rest of the brain [41]. In the present study, we found that opposite to $\left[{ }^{11} \mathrm{C}\right] \mathrm{DED}$ binding, GFAP and vimentin increased with $\mathrm{A} \beta$ pathology. MAO-B showed very limited co-localization with GFAP. The biochemical quantification of GFAP with
ELISA confirmed the results obtained with immunohistochemistry and indicated that increased GFAP levels were a consequence of, or at least mirrored, the A $\beta$ accumulation. These results are also supported by the previous studies in $\mathrm{APP}_{\text {swe }}$ mice and on post mortem human brain tissue [30, 42]. Another preclinical study, conducted in APP/PS1 mice, focusing on GABA function reported low degree of co- 

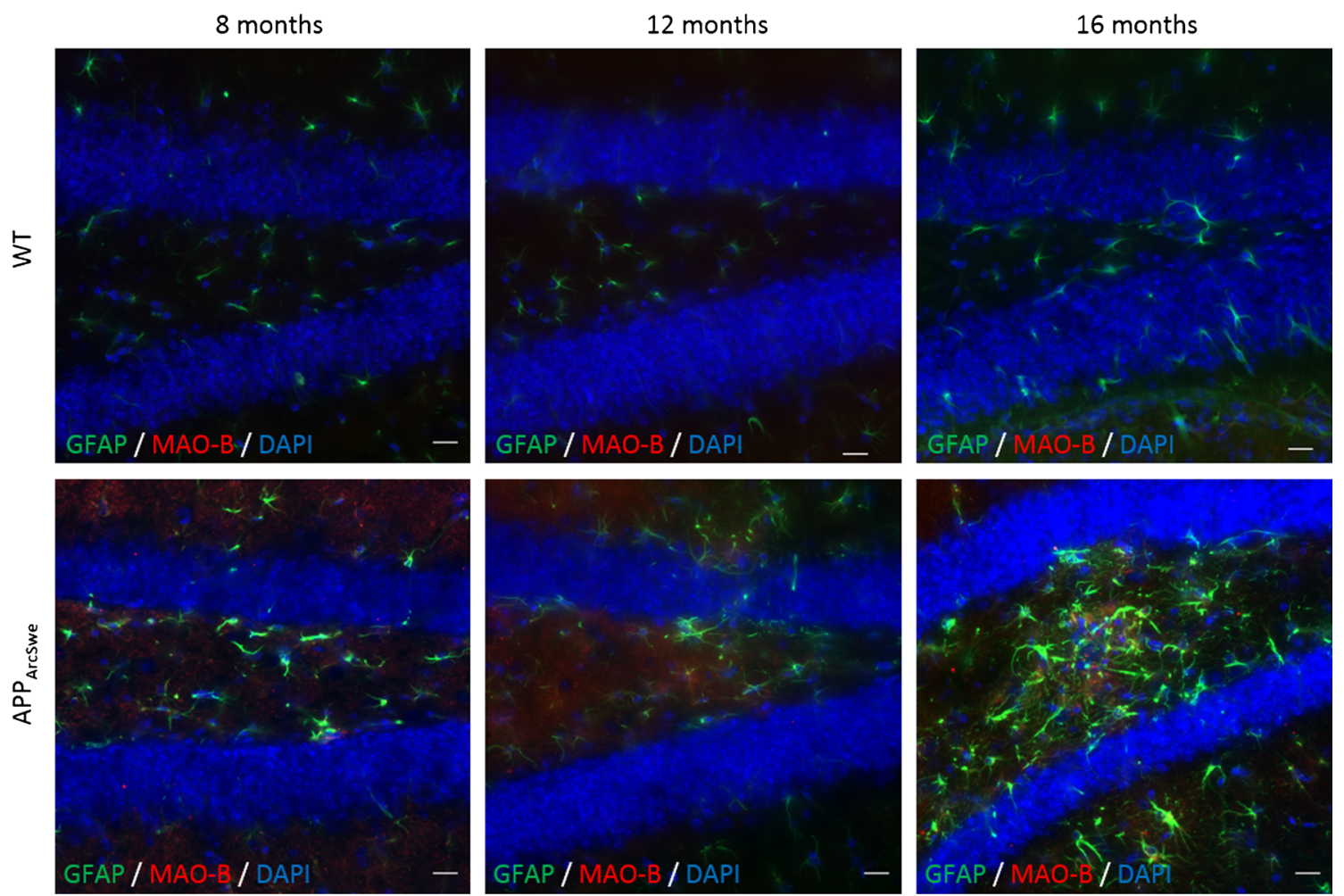

Fig. 5 Lack of co-localization between GFAP and MAO-B in hippocampus. Astrocytes are detected in green by anti-GFAP (Sigma Aldrich, G3893) and in red by anti-MAO-B (Sigma Aldrich, HPA002328). All images were taken at $\times 40$. Scale bars represent $20 \mu \mathrm{m}$.

localization of MAO-B and GFAP [43]. Thus, it appears that MAO-B and GFAP/vimentin could be markers for different stages of astrogliosis, or different types of astrocytes, or even completely different cell types, where MAO-B levels remain stable while GFAP/vimentin expression increase during $A \beta$ accumulation.

Another PET-imaging target related to neuroinflammation is the mitochondrial translocator protein (TSPO). TSPO
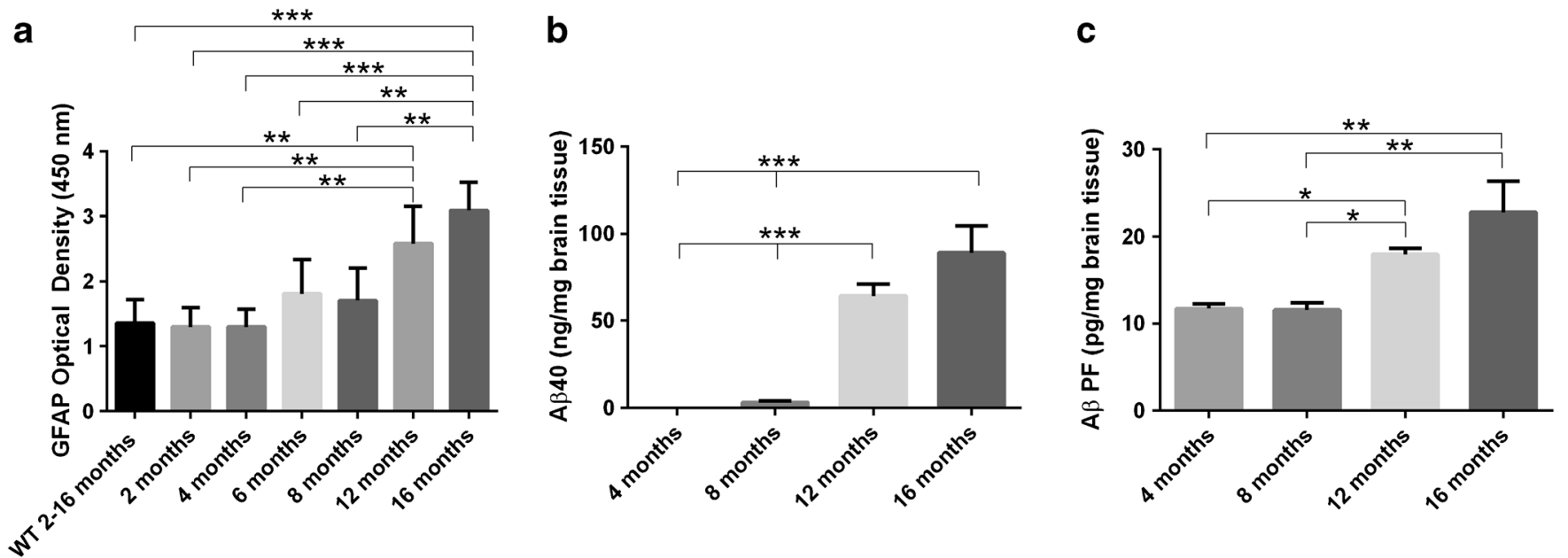

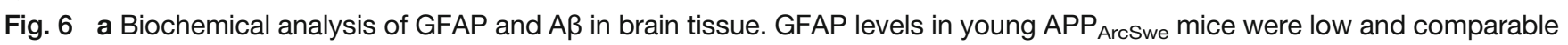

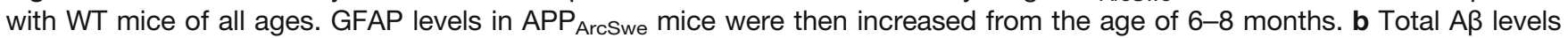
started to increase in APP ArcSwe $_{\text {a }}$ at months and were further increased at 16 months. c A protofibril levels in APP ArcSwe could be detected already at 4 months and increased further at 12 and 16 months. ( $n=4 \mathrm{APP}_{\text {ArcSwe }}, n=2 \mathrm{WT}$ per age group in (a), and $n=5$ per age group in (b) and (c)). 
is known to be upregulated in reactive microglia. Studies in mouse models of $A \beta$ pathology have shown that binding of TSPO PET radioligand $\left[{ }^{11} \mathrm{C}\right] \mathrm{PBR} 28$ was elevated in 6month-old 5× FAD transgenic mice compared with WT controls [44], while another TSPO ligand, $\left[{ }^{11} \mathrm{C}\right] \mathrm{PK} 11195$, displayed an age-dependent increase in binding in 13-19month-old $\mathrm{APP}_{\mathrm{Swe}} / \mathrm{PSEN1}_{\text {DeltaE9 }}$ mice [45]. Thus, TSPO imaging, in line with GFAP/vimentin, reflected level of $A \beta$ accumulation.

As of today, a number PET studies has been performed with $\left[{ }^{11} \mathrm{C}\right] \mathrm{DED}$ in human $\mathrm{AD}$ patients $[26-29,46,47]$. The majority of the published results show that the binding of $\left[{ }^{11} \mathrm{C}\right] \mathrm{DED}$ is increased in $\mathrm{AD}$ patients compared with healthy age-matched controls. Interestingly, it has been reported that the increase may be highest in MCI and prodromal $\mathrm{AD}$ indicating that astrogliosis measured by $\left[{ }^{11} \mathrm{C}\right] \mathrm{DED}$ is occurring early in the human $\mathrm{AD}$ brain $[26$, 27, 29]. Thus, the clinical studies are in line with the results obtained in the $\mathrm{APP}_{\text {ArcSwe }}$ mice in the present study.

The intrabrain accumulation of monomeric $A \beta$ and the formation of $\mathrm{A} \beta$ oligomers and protofibrils are likely to precede the formation of dense core plaques. We hypothesize that the increase in MAO-B levels may be a consequence of these soluble $A \beta$ species, which may be engulfed by astrocytes [20] and potentially be able to interact with MAO-B at the mitochondria. This hypothesis is also supported by earlier experiments in cell cultures showing that $A \beta$ 25-35 peptide induces expression of MAO-B in cultured rat astrocytes [48].

\section{Conclusions}

PET imaging with $\left[{ }^{11} \mathrm{C}\right] \mathrm{DED}$ is therefore a useful tool to diagnose neuroinflammation at an early stage in $\mathrm{AD}$. When analyzing changes in $\left[{ }^{11} \mathrm{C}\right] \mathrm{DED}$ binding, including a decline in binding as has been reported in some clinical studies when patients have progressed from $\mathrm{MCI} /$ prodromal $\mathrm{AD}$ to $\mathrm{AD}$, it is important to consider that such decline may not reflect a decline in astrogliosis per se. Different subclasses of astrocytes may express different proteins as a response to activation. The present study showed that changes in MAOB levels and GFAP/vimentin did not occur simultaneously and did not co-localize to the same cell population. Thus, a single marker such as MAO-B, GFAP, or vimentin, may not be enough for estimation of the total level of astrogliosis.

Acknowledgements. The authors acknowledge R.K. Selvaraju, S. Estrada, and V. Asplund at the Preclinical PET Platform, Uppsala University, Sweden, for excellent technical assistance with PET scanning and to Liza Al-Zaibari and Silvio R. Meier for assistance with the biochemical measurements of $A \beta$ and GFAP.

Funding This work was supported by Alzheimerfonden, Hjärnfonden, Åhlén-stiftelsen, Stohnes stiftelse, and Uppsala Berzelii Technology Centre for Neurodiagnostics.

Compliance with Ethical Standards. All mice used in this study were maintained under protocols approved by the Uppsala County Animal Ethics board, and followed the rules and regulations of the Swedish Animal Welfare Agency (approval number C17/14).

\section{Conflict of Interest}

The authors declare that they have no conflict of interest.

Open Access This article is distributed under the terms of the Creative Commons Attribution 4.0 International License (http:// creativecommons.org/licenses/by/4.0/), which permits unrestricted use, distribution, and reproduction in any medium, provided you give appropriate credit to the original author(s) and the source, provide a link to the Creative Commons license, and indicate if changes were made.

\section{References}

1. Hardy JA, Higgins GA (1992) Alzheimer's disease: the amyloid cascade hypothesis. Science 256(5054):184-185. https://doi.org/ 10.1126/science. 1566067

2. Hartley DM, Walsh DM, Ye CP, Diehl T, Vasquez S, Vassilev PM, Teplow DB, Selkoe DJ (1999) Protofibrillar intermediates of amyloid beta-protein induce acute electrophysiological changes and progressive neurotoxicity in cortical neurons. J Neurosci 19(20):8876-8884

3. Klyubin I, Walsh DM, Cullen WK, Fadeeva JV, Anwyl R, Selkoe DJ, Rowan MJ (2004) Soluble Arctic amyloid beta protein inhibits hippocampal long-term potentiation in vivo. Eur $\mathrm{J}$ Neurosci 19(10):2839-2846. https://doi.org/10.1111/j.1460-9568.2004.03389.x

4. Klyubin I, Cullen WK, NW H, Rowan MJ (2012) Alzheimer's disease Abeta assemblies mediating rapid disruption of synaptic plasticity and memory. Mol Brain 5(1):25. https://doi.org/10.1186/1756-6606-5-25

5. Walsh DM, Klyubin I, Fadeeva JV, Cullen WK, Anwyl R, Wolfe MS, Rowan MJ, Selkoe DJ (2002) Naturally secreted oligomers of amyloid beta protein potently inhibit hippocampal long-term potentiation in vivo. Nature 416(6880):535-539. https://doi.org/10.1038/416535a

6. Lacor PN, Buniel MC, Furlow PW, Sanz Clemente A, Velasco PT, Wood M, Viola KL, Klein WL (2007) Abeta oligomer-induced aberrations in synapse composition, shape, and density provide a molecular basis for loss of connectivity in Alzheimer's disease. J Neurosci 27(4):796-807. https://doi.org/10.1523/JNEUROSCI.350106.2007

7. Esparza TJ, Zhao H, Cirrito JR, Cairns NJ, Bateman RJ, Holtzman DM, Brody DL (2013) Amyloid-beta oligomerization in Alzheimer dementia versus high-pathology controls. Ann Neurol 73(1):104-119. https://doi.org/10.1002/ana.23748

8. Obulesu M, Jhansilakshmi M (2014) Neuroinflammation in Alzheimer's disease: an understanding of physiology and pathology. Int J Neurosci 124(4):227-235. https://doi.org/10.3109/ 00207454.2013 .831852

9. Bagyinszky E, Youn YC, An SSA, Kim S (2014) Characterization of inflammatory biomarkers and candidates for diagnos. BioChip Journal 8(3):155-162. https://doi.org/10.1007/s13206-014-8301-1

10. Eroglu C, Barres BA (2010) Regulation of synaptic connectivity by glia. Nature 468(7321):223-231. https://doi.org/10.1038/nature09612

11. Sofroniew MV, Vinters HV (2010) Astrocytes: biology and pathology. Acta Neuropathol 119(1):7-35. https://doi.org/10.1007/s00401009-0619-8

12. Verkhratsky A, Nedergaard M, Hertz L (2015) Why are astrocytes important? Neurochem Res 40(2):389-401. https://doi.org/10.1007/ s11064-014-1403-2

13. Pekny M, Wilhelmsson U, Pekna M (2014) The dual role of astrocyte activation and reactive gliosis. Neurosci Lett 565:30-38. https:// doi.org/10.1016/j.neulet.2013.12.071

14. Osborn LM, Kamphuis W, Wadman WJ, Hol EM (2016) Astrogliosis: an integral player in the pathogenesis of Alzheimer's disease. Prog Neurobiol 144:121-141. https://doi.org/10.1016/ j.pneurobio.2016.01.001

15. Cai Z, Hussain MD, Yan LJ (2014) Microglia, neuroinflammation, and beta-amyloid protein in Alzheimer's disease. Int J Neurosci 124(5):307-321. https://doi.org/10.3109/00207454.2013.833510

16. Sastre M, Klockgether T, Heneka MT (2006) Contribution of inflammatory processes to Alzheimer's disease: molecular mechanisms. Int J Dev Neurosci 24(2-3):167-176. https://doi.org/10.1016/ j.ijdevneu.2005.11.014 
17. Breunig JJ, Guillot-Sestier MV, Town T (2013) Brain injury, neuroinflammation and Alzheimer's disease. Front Aging Neurosci $5: 26$

18. Loov C, Hillered L, Ebendal T, Erlandsson A (2012) Engulfing astrocytes protect neurons from contact-induced apoptosis following injury. PLoS One 7(3):e33090. https://doi.org/10.1371/ journal.pone.0033090

19. Jones RS, Minogue AM, Connor TJ, Lynch MA (2013) Amyloidbeta-induced astrocytic phagocytosis is mediated by CD36, CD47 and RAGE. J NeuroImmune Pharmacol 8(1):301-311. https://doi.org/ 10.1007/s11481-012-9427-3

20. Sollvander S, Nikitidou E, Brolin R et al (2016) Accumulation of amyloid-beta by astrocytes result in enlarged endosomes and microvesicle-induced apoptosis of neurons. Mol Neurodegener 11(1):38. https://doi.org/10.1186/s13024-016-0098-z

21. Lindstrom V, Gustafsson G, Sanders LH et al (2017) Extensive uptake of alpha-synuclein oligomers in astrocytes results in sustained intracellular deposits and mitochondrial damage. Mol Cell Neurosci 82:143-156. https://doi.org/10.1016/j.men.2017.04.009

22. Nielsen HM, Mulder SD, Belien JA et al (2010) Astrocytic A beta 142 uptake is determined by a beta-aggregation state and the presence of amyloid-associated proteins. Glia 58(10):1235-1246. https:// doi.org/10.1002/glia.21004

23. Saura J, Bleuel Z, Ulrich J, Mendelowitsch A, Chen K, Shih JC, Malherbe P, da Prada M, Richards JG (1996) Molecular neuroanatomy of human monoamine oxidases A and B revealed by quantitative enzyme radioautography and in situ hybridization histochemistry. Neuroscience 70(3):755-774. https://doi.org/10.1016/S03064522(96)83013-2

24. Fowler JS, MacGregor RR, Wolf AP et al (1987) Mapping human brain monoamine oxidase $\mathrm{a}$ and $\mathrm{B}$ with $11 \mathrm{C}$-labeled suicide inactivators and PET. Science 235(4787):481-485. https://doi.org/ 10.1126/science.3099392

25. Gulyas B, Pavlova E, Kasa P et al (2011) Activated MAO-B in the brain of Alzheimer patients, demonstrated by [11C]-L-deprenyl using whole hemisphere autoradiography. Neurochem Int 58(1):60-68. https://doi.org/10.1016/j.neuint.2010.10.013

26. Choo IL, Carter SF, Scholl ML, Nordberg A (2014) Astrocytosis measured by (1)(1)C-deprenyl PET correlates with decrease in gray matter density in the parahippocampus of prodromal Alzheimer's patients. Eur J Nucl Med Mol Imaging 41(11):2120-2126. https:// doi.org/10.1007/s00259-014-2859-7

27. Carter SF, Scholl M, Almkvist O, Wall A, Engler H, Langstrom B, Nordberg A (2012) Evidence for astrocytosis in prodromal Alzheimer disease provided by $11 \mathrm{C}$-deuterium-L-deprenyl: a multitracer PET paradigm combining 11C-Pittsburgh compound B and 18F-FDG. J Nucl Med 53(1):37-46. https://doi.org/10.2967/jnumed.110.087031

28. Rodriguez-Vieitez E, Carter SF, Chiotis K, Saint-Aubert L, Leuzy A, Scholl M, Almkvist O, Wall A, Langstrom B, Nordberg A (2016) Comparison of early-phase 11C-deuterium-1-deprenyl and 11CPittsburgh compound B PET for assessing brain perfusion in Alzheimer disease. J Nucl Med 57(7):1071-1077. https://oi.org/ 10.2967/jnumed.115.168732

29. Rodriguez-Vieitez E, Saint-Aubert L, Carter SF, Almkvist O, Farid K, Schöll M, Chiotis K, Thordardottir S, Graff C, Wall A, Långström B, Nordberg A (2016) Diverging longitudinal changes in astrocytosis and amyloid PET in autosomal dominant Alzheimer's disease. Brain 139(3):922-936. https://doi.org/10.1093/brain/awv404

30. Rodriguez-Vieitez E, Ni R, Gulyas B et al (2015) Astrocytosis precedes amyloid plaque deposition in Alzheimer APPswe transgenic mouse brain: a correlative positron emission tomography and in vitro imaging study. Eur J Nucl Med Mol Imaging 42(7):1119-1132. https://doi.org/10.1007/s00259-015-3047-0

31. Simpson JE, Ince PG, Lace G, Forster G, Shaw PJ, Matthews F, Savva G, Brayne C, Wharton SB, MRC Cognitive Function and Ageing Neuropathology Study Group (2010) Astrocyte phenotype in relation to Alzheimer-type pathology in the ageing brain. Neurobiol Aging 31(4):578-590. https://doi.org/10.1016/ j.neurobiolaging.2008.05.015

32. Philipson O, Lord A, Gumucio A, O'Callaghan P, Lannfelt L, Nilsson LNG (2010) Animal models of amyloid-beta-related pathologies in
Alzheimer's disease. FEBS J 277(6):1389-1409. https://doi.org/ 10.1111/j.1742-4658.2010.07564.x

33. Lord A, Kalimo H, Eckman C, Zhang XQ, Lannfelt L, Nilsson LNG (2006) The Arctic Alzheimer mutation facilitates early intraneuronal Abeta aggregation and senile plaque formation in transgenic mice. Neurobiol Aging 27(1):67-77. https://doi.org/10.1016/ j.neurobiolaging.2004.12.007

34. Sehlin D, Fang XT, Cato L, Antoni G, Lannfelt L, Syvänen S (2016) Antibody-based PET imaging of amyloid beta in mouse models of Alzheimer's disease. Nat Commun 7:10759. https://doi.org/10.1038/ ncomms10759

35. Kumlien E, Bergstrom M, Lilja A, Andersson J, Szekeres V, Westerberg CE, Westerberg G, Antoni G, Langstrom B (1995) Positron emission tomography with [11C]deuterium-deprenyl in temporal lobe epilepsy. Epilepsia 36(7):712-721. https://doi.org/ 10.1111/j.1528-1157.1995.tb01051.x

36. Loening AM, Gambhir SS (2003) AMIDE: a free software tool for multimodality medical image analysis. Mol Imaging 2(3):131-137. https://doi.org/10.1162/153535003322556877

37. Ma Y, Hof PR, Grant SC, Blackband SJ, Bennett R, Slatest L, McGuigan MD, Benveniste H (2005) A three-dimensional digital atlas database of the adult C57BL/6J mouse brain by magnetic resonance microscopy. Neuroscience 135(4):1203-1215. https://doi.org/10.1016/ j.neuroscience.2005.07.014

38. Lammertsma AA, Hume SP (1996) Simplified reference tissue model for PET receptor studies. NeuroImage 4(3):153-158. https://doi.org/ 10.1006/nimg. 1996.0066

39. Sehlin D, Englund H, Simu B, Karlsson M, Ingelsson M, Nikolajeff F, Lannfelt L, Pettersson FE (2012) Large aggregates are the major soluble Abeta species in AD brain fractionated with density gradient ultracentrifugation. PLoS One 7(2):e32014. https://doi.org/10.1371/ journal.pone.0032014

40. Magnusson K, Sehlin D, Syvanen S et al (2013) Specific uptake of an amyloid-beta protofibril-binding antibody-tracer in AbetaPP transgenic mouse brain. J Alzheimers Dis 37(1):29-40. https://doi.org/ 10.3233/JAD-130029

41. Petito CK, Morgello S, Felix JC, Lesser ML (1990) The two patterns of reactive astrocytosis in postischemic rat brain. J Cereb Blood Flow Metab 10(6):850-859. https://doi.org/10.1038/jcbfm.1990.141

42. Marutle A, Gillberg PG, Bergfors A et al (2013) (3)H-deprenyl and (3)H-PIB autoradiography show different laminar distributions of astroglia and fibrillar beta-amyloid in Alzheimer brain. J Neuroinflammation 10:90

43. Jo S, Yarishkin O, Hwang YJ, Chun YE, Park M, Woo DH, Bae JY, Kim T, Lee J, Chun H, Park HJ, Lee DY, Hong J, Kim HY, Oh SJ, Park SJ, Lee H, Yoon BE, Kim YS, Jeong Y, Shim I, Bae YC, Cho J, Kowall NW, Ryu H, Hwang E, Kim D, Lee CJ (2014) GABA from reactive astrocytes impairs memory in mouse models of Alzheimer's disease. Nat Med 20(8):886-896. https://doi.org/10.1038/nm.3639

44. Mirzaei N, Tang SP, Ashworth S, Coello C, Plisson C, Passchier J, Selvaraj V, Tyacke RJ, Nutt DJ, Sastre M (2016) In vivo imaging of microglial activation by positron emission tomography with [(11)C]PBR28 in the 5XFAD model of Alzheimer's disease. Glia 64(6):993-1006. https://doi.org/10.1002/glia.22978

45. Venneti S, Lopresti BJ, Wang G, Hamilton RL, Mathis CA, Klunk WE, Apte UM, Wiley CA (2009) PK11195 labels activated microglia in Alzheimer's disease and in vivo in a mouse model using PET. Neurobiol Aging 30(8):1217-1226. https://doi.org/10.1016/ j.neurobiolaging.2007.11.005

46. Hirvonen J, Kailajarvi M, Haltia T et al (2009) Assessment of MAO-B occupancy in the brain with PET and [11C]-L-deprenyl-D2: a dosefinding study with a novel MAO-B inhibitor. Clin Pharmacol Ther 85(5):506-512. https://doi.org/10.1038/clpt.2008.241

47. Santillo AF, Gambini JP, Lannfelt L, Långström B, Ulla-Marja L, Kilander L, Engler H (2011) In vivo imaging of astrocytosis in Alzheimer's disease: an (1)(1)C-L-deuteriodeprenyl and PIB PET study. Eur J Nucl Med Mol Imaging 38(12):2202-2208. https:// doi.org/10.1007/s00259-011-1895-9

48. Song W, Zhou LJ, Zheng SX, Zhu XZ (2000) Amyloid-beta 25-35 peptide induces expression of monoamine oxidase B in cultured rat astrocytes. Acta Pharmacol Sin 21(6):557-563 